Introduction Constructive ergonomics is characterised by a developmental and participatory approach of occupational health involving the workers at every stage of the prevention intervention. Philosophically, the worker is conceptualised as an active person engaged with his own values in a complex social and technical environment, and able to (re)act on this environment. Work can be therefore either a resource for personal development and well-being or a source of negative health effects and ethical conflicts in case of contradiction between the work physical, mental and emotional demands and workers' capabilities or personal values. The concept of 'operational leeway' is defined by the space of freedom available or constructed by workers individually or collectively, to elaborate alternative ways of working and strategies according to their skills, knowledge and values in order to achieve production targets while reducing as much as possible the psychological, mental and physical strains and avoiding negative health effects.

Methods We will explain the similarities between the concepts of constructive ergonomics, capabilities and effective freedom of choice - proposed by the economist and philosopher Amartya Sen -, and workers' power to act developed by the French philosopher Paul Ricoeur. According to ergonomics of activity, workers' power to act may be created when operational leeway and capabilities are sufficient to allow workers developing their own working strategies and skills according to their personal values. According to constructive ergonomics, implementing work situations and work organisation allowing the development of sufficient operational leeway and power to act is a key issue to promote workers' health and sustainable working conditions.

Discussion Constructive ergonomics argues in favour of a developmental perspective of health at work. Its usefulness to improve strategies of promotion of health at work and promote integrated approaches of the prevention in Occupational Health will be discussed.

\section{$1645 f$ DESPITE THE GAPS, PURSUING ON A WORKPLACE CULTURE OF KINDNESS}

J Rodriguez-Guzman*, F Herrera. Regional Advisor on workers' and Consumers' Health, Pan-American Health Organisation/World Health Organisation (PAHOWHO), Washington, $D C$

\subsection{6/oemed-2018-ICOHabstracts.617}

Efforts to protect people's health and wellbeing in the Region of the Americas have evolved to activate massive and collective health promotion activities for workers throughout the region. For this purpose, PAHO organises and celebrates Wellness Week to promote healthy living, healthy working and healthy life styles since 2011. Facing the burdens of modern work and the ways technology, globalisation and human relationships have changed, we examined the advances done since the campaign launched in 2014 aiming to make workplace kindness a cultural value, followed by the respectful workplace policy issued in 2015; the campaign to create awareness and manage workplace stress in 2016; and the latest advance towards positive organisation and enhancing resilience at the workplace in 2017.

After developing each yearly activity, reports on the results of were made showing their impressive impact. Activities carried out had different levels of results. Very positive testimonies expressing gratefulness for the actions taken and embracing satisfaction, empowerment and sense of pertinence to the workplace. However, the persistent presence of stressful working conditions and challenges during work processes were acknowledged, affecting work-life balance and their physical and mental health. As well, employment conditions were also mentioned as a source of stress and dissatisfaction.

To improve workplace performance, further actions are needed to:

- address specific psychosocial risks;

- integrate organisational strategies for enhancing healthy and positive organisational skills;

- promote protective psychosocial and behavioural factors; and

- promote modifications to workstyles.

All together will allow to address the gaps that still persist.

\section{$1645 \mathrm{~g}$ THE EXPERIENCE OF WORK}

R Nicholas. Robin Nicholas Communications, Santa Fe, NM, USA

\subsection{6/oemed-2018-ICOHabstracts.618}

Introduction In its most ideal state, work can provide an opportunity for us to experience and explore ourselves through our work. We can experience ourselves through our identity, our understanding as a whole person, our core values, our internal motivations, and our behaviours that arise from our core values and motivations.

Methods One way to explore all this is through the practice of inquiry-simply by asking, who are we when we work? The answer is not some kind of intellectual exercise where we analyse or quantify ourselves. Instead, the answer comes from how we experience ourselves, our coworkers, and the work itself.

Results In the right work environment, we have the opportunity to experience ourselves in ways that are unique for each of us. We can come to understand ourselves through our work-through our awareness, our relationships, our selfexcellence, and how we bring our whole selves, our human spirit, to our work. When work nourishes the human spirit, we can live the greater parts of ourselves. This is the potential experience of the whole person, because indeed, each person is greater than the sum of their parts.

Discussion Because of who we are at work, we can dedicate ourselves to our families, we can learn and grow, we can create, and we can contribute to something bigger than ourselves. The ultimate gift of work is that experiencing ourselves at work can lead to experiencing ourselves in life. The reverse is equally true, because who we are in life is who we are at work. Keats wrote, 'Nothing ever becomes real till it is experienced.' Work has the potential to provide that real experience. 


\section{International Collaborations}

\section{BRINGING TOGETHER OCCUPATIONAL AND ENVIRONMENTAL MEDICINE SPECIALISTS - DEVELOPMENT OF THE INTERNATIONAL OCCUPATIONAL MEDICINE SOCIETY COLLABORATIVE (IOMSC)}

Richard JL Heron*. Vice-President, Health and Chief Medical Officer, BP International Ltd, Middlesex, UK

\subsection{6/oemed-2018-ICOHabstracts.619}

Introduction In 2013, ACOEM and SOM convened leaders from national occupational medical societies to discuss mutual issues in global occupational and environmental medicine (OEM) and established the International Occupational Medicine Society Collaborative (IOMSC). IOMSC's mission is to improve workers' health and workplace safety on a global scale. It provides OEM societies opportunities to gain the knowledge and expertise required of OEM physicians; tools/ resources to educate their members; practices by what has been proven to work; and the ability to reach all global regions with more effective OEM care. Its active participants are delegates appointed by occupational medical organisations, world over, and currently includes 40 societies in 36 countries.

Methods IOMSC conducted a member survey (July 2015) to quantify the reach of IOMSC globally and identify common modes of OEM practice and key changes in the workplace. IOMSC plans to develop projects to address challenges identified (e.g., assist with education/training of physicians to share best practices; summarise scope of OEM practice in a position paper; develop guidebook on how to establish and promote the role of the society).

Result Survey results $(n=21)$ indicated that OEM practitioners encounter similar challenges including the growing complexity of diseases/illnesses; rapid change in workforce and population trends; and shifting legislative and economic policies that impact the profession. Scope and delivery mode of OEM services varies widely among countries, being influenced by governmental/regulatory structures.

Discussion With IOMSC, OEM societies can create a strong case to explain the value of OEM to employers, workers, the medical community, and governments. IOMSC can help increase awareness of OEM in terms of using its preventive strategies and risk assessments to prevent injury/illness and helping employers understand the value of good health in enhancing productivity and profit. IOMSC is well positioned to address professional issues and advance OEM through education, sharing best practices, and advocacy.

\section{WHAT IS THE GLOBAL IMPACT OF THE NEW (2016) OSHA SILICA DUST STANDARD?}

David F Goldsmith*. George Washington University, Washington DC, USA

\subsection{6/oemed-2018-ICOHabstracts.620}

Introduction In 2016 the U.S. Occupational Safety and Health Administration (OSHA) completed a new standard for workplace crystalline silica. We are trying to understand what this will mean outside the U.S.

Methods/current situation On March 24, 2016 OSHA issued a revised silica dust rule setting levels in construction and general industry at $50 \mathrm{ug} / \mathrm{m} 3$ for 8 hour workday- $1 / 2$ of the $100 \mathrm{ug} / \mathrm{m} 3$ previous standard. More information available https://www.federalregister.gov/documents/2016/03/25/201604800/occupational-exposure-to-respirable-crystalline-silica. OSHA is now labelling respirable silica a known human carcinogen, as it has been judged by IARC since 1996. In addition to silica being known to cause silicosis, it is now judged to be linked with auto-immune and kidney diseases. The new rule expected to save 600 lives and 900 cases of silicosis annually in U.S.

Results The World Health Organisation (WHO) is leading efforts to document the numbers of silicosis cases worldwide. Although the rates of silicosis have declined in most industrialised nations, they appear to be steady or rising in Asia, Africa, South America and the former Soviet Union. In South Africa, there is a strong effort to control silica dust because it is linked with excess silico-tuberculosis (silicoTB), especially in migrant gold miners. OSHA is likely to be asked by other global regulatory agencies to share their work, though we do not expect the new administration to be very supportive. There may be some collaboration to study nonsilicosis lung diseases, lung cancer and other cancer endpoints in countries such as South Africa, China and Chile. In the Philippines there have not been any published research, but there should be a focus on education of miners and construction workers.

Discussion The new OSHA silica rule may spur other nations to adopt the new $50 \mathrm{ug} / \mathrm{m}^{3}$ standard, to undertake novel research studies, and to offer education to alert workers to silica's health risks.

\section{FUTURE OF WORK AND OCCUPATIONAL SAFETY AND HEALTH: AN OVERSIGHT OF THE NORDIC FUTURE OF WORK AND OSH REPORT}

${ }^{1}$ Yogindra Samant, ${ }^{2}$ Magnus Falk, ${ }^{3}$ Päivi Mattila-Wiro, ${ }^{4}$ Sture Bye, ${ }^{5}$ Oscar Vargas, ${ }^{6}$ Xabier Irastorza, ${ }^{7}$ Nancy Leppink. ${ }^{1}$ Norwegian Labour Inspection Authority, Trondheim, Norway; ${ }^{2}$ Work Environment Authority, Stockholm, Sweden; ${ }^{3}$ Ministry of social affairs and health, Tampere, Finland; ${ }^{4}$ National Institute of Occupational Health, Oslo, Norway; ${ }^{5}$ European foundation for the Improvement, Dublin, Ireland; ${ }^{6}$ European Agency for Safety and Health at Work, Bilbao, Spain; International Labour Organization, Geneva, Switzerland

\subsection{6/oemed-2018-ICOHabstracts.621}

Introduction In 2016 representatives from different state organisations working with $\mathrm{OSH}$ in the Nordic countries joined up to identify challenges in work and work life today and tomorrow. The principal aim after that was to formulate ideas on how to tackle these challenges - and present recommendations to the national labour inspectorates based on this. The report is entitled Diversity of the future workforce and work tasks - challenges to OSH.

Results Pace of change within the work market in the Nordic countries is fast, it brings a high degree of complexity, and the identified challenges begs the attention of the labour inspections to prepare in advance. The report states that there is a need to look more closely on (amongst others): the changing nature of work and its location - safety 